\title{
O DESAFIO DO DOCENTE DE EDUCAÇÃO FÍSICA DE INSTITUIÇÕES DE ENSINO SUPERIOR: ENSINAR NA SOCIEDADE DO CONHECIMENTO
}

\author{
Brunna Galtierrez Fortes Pessoa (UNIFSA) ${ }^{1}$ \\ Robert Maurício de Oliveira Araújo (UNIFSA) ${ }^{2}$
}

\section{RESUMO}

A docência superior na Sociedade do Conhecimento constitui-se em campo de amplas discussões acadêmicas tendo em vista o seu caráter plural, marcado pelo acelerado ritmo de mudanças associadas à diversidade das Tecnologias de Informação e Comunicação e às novas exigências sociais e normativas que permeiam o ensino superior. A presente pesquisa objetivou investigar como se caracteriza a docência no curso de Educação Física de Instituições de Ensino Superior frente às novas exigências da sociedade do conhecimento e o processo de ensino e aprendizagem. Foi realizada uma revisão de literatura em livros, destacando-se as obras de Behrens (2013), Belloni (2008), Lévy (2003), Moran (2013), Masetto (2012) e outros artigos selecionados nas bases de dados do Portal de Periódicos CAPES, em um recorte temporal de 2008 e 2018. Após análise dos textos selecionados, foi possível constatar que o contexto da Sociedade do Conhecimento e protagonista de mudanças de tempos, espaços, metodologias, recursos e ações educativas associados ao acelerado fluxo de informações e gradual acesso a estas via TIC's. Conclui-se que a docência superior na Educação Física precisa passar por profundas mudanças frente às novas exigências contextuais, como também, de maiores investimentos no campo da produção acadêmica, divulgação e discussão acerca das práticas pedagógicas inovadoras e da utilização de recursos tecnológicos para a formação de profissionais autônomos, críticos e transformadores.

Palavras-Chave: Docência Superior. Sociedade do Conhecimento. Educação Física.

\section{INTRODUÇÃO}

O contexto social na atualidade destaca-se pela velocidade e volume na geração, no processamento e na transmissão das informações alterando substantivamente a intensidade com que os mecanismos de produção e dominação atuam, nos quais o acesso e uso da informação encontram-se no cerne das discussões. (CASTELLS, 2000). Em outros termos, vive-se na sociedade do conhecimento onde as tecnologias da informação e comunicação protagonizam transformações ao alterarem as formas como nos comunicamos, e acessamos informações.

\footnotetext{
${ }^{1}$ Pós-graduada em Docência no Ensino Superior (UNIFSA). Graduada em Educação Física (UFPI). E-mail: brunnagaltierrez@hotmail.com

${ }^{2}$ Professor Orientador. Mestre em Educação (UFPI). Docente do centro Universitário Santo Agostinho (UNIFSA). Email: robpi202@gmail.com
} 
A educação de forma geral e o ensino superior em particular, inseridos em uma sociedade do conhecimento não ficam isentos de suas influências, ou seja, sobressaem-se novas demandas no âmbito da docência no Ensino Superior que segundo o Instituto Nacional de Estudos e Pesquisas Educacionais - INEPE, em estudo realizado no ano de 2016 acerca do perfil dos discentes de ensino superior no Brasil aponta para os seguintes dados: possui renda familiar de no máximo, $\mathrm{R} \$$ 2.640; é branco (51,7\%); solteiro (74,4\%); mora com os pais ou parentes $(54,6 \%)$; não trabalha; não tem renda $(54,5 \%)$ e dedica no máximo a 3 horas de estudos semanais extraclasse: enfrentam um novo momento e deve adequar-se a realidade atual.

O mercado de trabalho atual requer profissionais que saibam trabalhar em equipe e que produza conhecimento fidedigno necessitando-se para isso que a aprendizagem seja continua e que se atualizem constantemente. (CORRÊA, FRANÇA, BEZERRA, 2015).

O instituto Nacional de Estudos e Pesquisas educacionais Anísio Teixeira (Inep) em seu último censo divulgado, baseado nos dados obtidos por meio do Exame Nacional de desempenho (ENADE) 2016, revela que o perfil dos discentes de ensino superior no Brasil é o que tem renda familiar de no máximo $\mathrm{R} \$ 2.640$; é branco $(51,7 \%)$; solteiro $(74,4 \%)$; mora com os pais ou parentes $(54,6 \%) ;$ não trabalha; não tem renda $(54,5 \%)$ e dedica no máximo a 3 horas de estudos semanais extraclasse, $20,4 \%$ ingressaram no ensino superior por meio de politicas de afirmação ou inclusão social, deste percentual, 35,4\% pela razão de terem estudado em escola pública ou particular com bolsa, 30,1\% por meio de critérios de renda; e 10\% pelo critério étnico-racial.

Em vista disso é crescente o fluxo de produções acadêmicas que tematizam práticas pedagógicas inovadoras, metodologias ativas e tecnologias de ensino e aprendizagem que contemplem as constantes exigências que o contexto da formação inicial imerso em uma sociedade do conhecimento propõe, das quais se podem citar os trabalhos de Behrens (2013), Belloni (2008), Moran (2013), Masetto (2012), Piva Junior, (2013). Nesta perspectiva, ressalta-se a problemática da docência superior dos cursos de Educação Física frente às novas demandas educacionais.

A presente pesquisa consistiu em saber como se caracteriza a docência no curso de Educação Física de Instituições de Ensino Superior frente às novas exigências da sociedade do conhecimento e o processo de ensino e aprendizagem. Como objetivos específicos, propôs-se analisar a relação da sociedade do conhecimento com as Instituições de Ensino Superior, 


\section{CONQGEESOO CIENCIAESOCIEDADE

caracterizar a docência superior da educação física, seus avanços e obstáculos e sugerir formas de usar as tecnologias da informatização e comunicação no processo de ensino e aprendizagem.

\section{METODOLOGIA (OU MATERIAL E MÉTODOS)}

A metodologia escolhida para desenvolver este trabalho foi a pesquisa bibliográfica, que segundo Gil (1991) é baseado em material já publicado. Onde foi feito um levantamento bibliográfico, por meio de leitura seletiva, e como técnica de pesquisa utilizada o fichamento.

O levantamento bibliográfico foi realizado de julho a setembro de 2018 no qual foram incluídos livros impressos e artigos indexados. Dentre os livros utilizados na fundamentação desta pesquisa destacam-se as obras de Behrens (2013), Belloni (2008), Lévy (2003), Moran (2013), Masetto (2012), Piva Junior, (2013), dentre outros. Os artigos, por sua vez, foram selecionados após levantamento bibliográfico nas bases de dados do Portal de Periódicos CAPES utilizando-se as palavras-chave "docência", "educação física", nos idiomas português e espanhol, dentro do recorte temporal de 2008 e 2018.

\section{RESULTADOS E DISCUSSÃO}

O contexto social na atualidade caracteriza-se, dentre outros aspectos, pelo acelerado ritmo de transformações que se concretizam em escala mundial em todos os setores que compõe a sociedade, impulsionado pelo avanço exponencial das novas tecnologias da informação e da comunicação, frutos da mudança do modelo de sociedade industrial baseada na produção de bens materiais para a sociedade do conhecimento com uso intensivo de tecnologias. (BEHRENS, 2013).

A sociedade do conhecimento surge com o pós-industrialismo, a globalização, ampliando seu alcance com a popularização da Internet e das novas tecnologias como ambiente de produção de conhecimentos em meio a enorme quantidade de informações em que as pessoas atualmente estão expostas. (CORRÊA, FRANÇA, BEZERRA, 2015).

O termo Sociedade do Conhecimento refere-se ao contexto marcado pela pluralidade de fontes de produção do conhecimento e pela ampliação da socialização do conhecimento através dos meios de comunicação, em tempo real, de forma a permitir que o conhecimento fosse produzido em diferentes lugares e não somente no ambiente universitário. (MASETTO, 2012). 
O papel protagonista das TIC's ${ }^{3}$ na constituição da Sociedade do Conhecimento teve como consequência imediata a criação do que se conhece como ciberespaço, ou seja, segundo Lévy (2003, p.17) trata-se de um:

novo meio de comunicação que surge da interconexão mundial dos computadores. 0 termo especifica não apenas a infraestrutura material da comunicação digital, mas também o universo oceânico de informações que ela abriga, assim como os seres humanos que navegam e alimentam esse universo.

O ciberespaço fez com que a comunicação passasse a acontecer de forma interativa e comunitária, e mostrou-se também como um dispositivo que favorece a inteligência coletiva, visto que possibilita a formação de comunidades, dos mais variados tipos e tamanhos em coletivos inteligentes permitindo a interação delas entre si. (LÉVY, 2003).

Na Sociedade do Conhecimento, a conexão estabelecida entre as pessoas por intermédio dos recursos tecnológicos vem possibilitando novas formas de interação entre os pares, diferentes relações com o saber, inovações nas maneiras com que as pessoas se comunicam e ensinam; constituindo um processo contínuo de integração entre o individual, o grupal, o social e as novas tecnologias. (MORAN, 2013, p.68).

Neste contexto, o aumento da demanda por múltiplas atividades de pesquisa, de relacionamentos, entre outros serviços, trouxeram mudanças profundas na educação e nas formas de ensinar e aprender, como também, a necessidade de estar em constante processo de atualização, tendo em vista a velocidade com que o conhecimento é construído e descartado. (BEHRENS, 2013; MORAN, 2013). As instituições de ensino, frente a essas novas exigências que emanam do contexto social, necessitam rever seus projetos educativos, repensar suas metodologias, visto que:

os perfis de sujeitos a serem preparados para o mercado de trabalho, exige novos métodos de pensamento, novas ferramentas, menos lineares e mais hipermidiáticas ou hipertextuais, focalizando um novo caminho para a aprendizagem, com ênfase não mais no produto, e sim no processo. (BARBOSA 2005, p.53).

Sendo assim as IES devem promover as mudanças necessárias para atender as exigências da sociedade do conhecimento. (MASETTO, 2012). Para que assim possa ofertar uma formação compatível com o momento atual. Tendo para isso de rever como será a "construção e socialização do conhecimento, formação de profissionais competentes e cidadãos,

\footnotetext{
${ }^{3}$ Abreviação do termo Tecnologias da Informação e Comunicação.
} 
desenvolvimento da pesquisa, revisão das carreiras profissionais e exigências axiológicas." (MASETTO, 2012, p. 21).

Trabalhos como os de Behrens (2013) e Leite (2011) apontam para uma mudança de paradigma na educação no sentido de que não há mais espaço para uma prática de ensino que seja conservadora, repetitiva e acrítica, ou seja, que o ensino baseado na metodologia tradicional onde apenas transmite a informação e o aluno tem de memorizar, não condiz mais com a realidade atual, que de forma progressiva exige uma educação alinhada ao paradigma da complexidade ${ }^{4}$; por seu caráter de ser aberto, interdisciplinar, colaborativo e hipertextual ${ }^{5}$.

É válido ressaltar que a mudança de paradigma educacional não implica somente incluir as tecnologias da informação e comunicação e deixar as informações disponíveis nesse meio eletrônico, para tal, é necessário que o sujeito da aprendizagem se aproprie da informação e atribua significado a esta. Para isso a instituição de ensino superior precisa problematizar, desafiar e fazer com que as pessoas construam o conhecimento de maneira colaborativa e de forma crítica. (COSTA, PAIM, 2004; LEITE, 2011).

Portanto, a inclusão das TIC's exigirá que essas instituições tenham projetos educacionais bem definidos que objetive por meio de seu uso a ampliação das experiências formativas no sentido de consolidar em cada estudante o "aprender a aprender", "aprender a fazer", "aprender a conviver" e o "aprender a ser", numa perspectiva crítica e transformadora cujo propósito seja a formação de indivíduos que saibam ler e intervir para transformar a sociedade ao invés de apenas se adequar a esta.

Estudos sobre políticas educacionais no ensino superior apontam que as mudanças de ordem política e econômica como o neoliberalismo, a globalização e a reestruturação produtiva, pelas quais a sociedade vem passando, provocam alterações em vários setores da sociedade incluindo a educação e, por conseguinte influenciam a área da Educação Física, através das mudanças nas diretrizes, leis e parâmetros. (SILVA, 2013).

O profissional de Educação Física, até a década de 1970, tinha sua atuação limitada à escola, atendendo a demanda escolar e cuja formação inicial possuía caráter predominantemente

\footnotetext{
4 Paradigma da Complexidade caracteriza-se pela análise conjunta de todos os elementos/ dimensões de uma problemática em oposição à análise fragmentada que até então vem predominando nas ciências e no ensino moderno. (LEITE, 2011, p.72)

${ }^{5}$ Hipertexto é um conjunto de nós ligados por conexões. Os nós podem ser palavras, páginas, imagens, gráficos ou

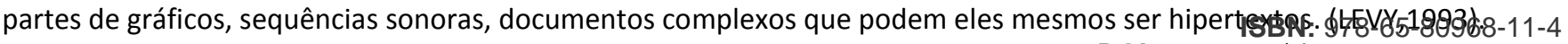


instrumental e dissociado dos problemas sociais. Com o processo de abertura política, em meados da década de 1980, e a importante contribuição das ciências humanas, no arcabouço teórico da Educação Física, contribuiu para o surgimento de uma série de questionamentos acerca da relevância, alcance e estatuto científico desta área do conhecimento fazendo com que a mesma entrasse em um estado de "crise de identidade". (MEDINA, 2000).

Associado às mudanças contextuais e paradigmáticas pelas quais a sociedade e a Educação Física vieram atravessando, o mercado passou a necessitar também de um profissional que atendesse às novas demandas da sociedade, ou seja, a exigência de um profissional de Educação Física qualificado e atualizado com as progressivas mudanças no contexto e em seus atores.

Por um lado, a escola exigia uma formação docente que superasse a instrumentalidade técnica e a fragmentação/dissociação do saber, por outro lado, a formação generalista que o profissional de Educação Física possuía não atendia mais às demandas do ambiente escolar e nem às do contexto extraescolar. Nesta perspectiva surge o curso de Bacharelado em Educação Física com o propósito de atender de forma qualificada e atualizada a demanda dos praticantes de exercícios físicos no contexto extraescolar. (SILVA, 2013).

Por meio das Diretrizes Curriculares Nacionais, aprovadas pelo CNE/MEC (Resolução 03/87CFE) a formação superior em Educação Física foi subdivida em licenciatura e bacharelado. (DAVID, 2009). A partir daí o campo da Educação Física passou a ter dois perfis de profissionais, o licenciado que atua em escolas com o objetivo de veicular a cultura corporal do movimento de maneira pedagógica e o bacharel que trata a cultura corporal do movimento como uma mercadoria que a vende em forma de serviços de saúde e lazer. (SILVA, 2013).

Coube, portanto, às instituições de ensino superior direcionar seus projetos curriculares para garantir essas formações de maneira que cada uma delas tenham sua própria identidade e terminalidade, formando profissionais com competências que atendam a demanda do mercado e do sistema produtivo social, assim como, reestruturar suas matrizes curriculares de forma a proporcionar uma formação inicial que contemple às novas diretrizes, expressas através das Resoluções CNE/CP $n^{\circ}$ 1/2002, CNE/CES $n^{\circ} 7 / 2004$, CNE/CP $n^{\circ}$ 2/2002 referentes ao curso de Licenciatura em Educação Física e às Resoluções CNE/CES n 7/2004 e CNE/CES n 4/2009 referentes ao curso de Bacharelado (DAVID, 2009).

Diante deste cenário, aos docentes de Educação Física de instituições de ensino superior é esperado que: 
Atualize seus saberes na área de trabalho para assimilar mudanças profissionais impostas a profissão e saber introduzi-las positivamente na formação de seus alunos; que tenha uma prática marcada pela reflexão e análise da importância das competências, seja no terreno da prática ou da teoria; que conheça e reconheça conteúdos convergentes ás aspirações discentes e, mais que isso, estimule neles outras aspirações para que construam outros campos de atuação profissional e desenvolvam outras competências e outros saberes. (PASEKINE, 2010, p. 48)

Conforme expresso anteriormente, infere-se que, apesar das mudanças ocorridas no âmbito da formação inicial no curso de Educação Física, o contexto da docência superior nesta área e seus desafios não diferem do contexto da docência superior dos demais cursos. A utilização de metodologias inovadoras, de novas tecnologias, de práticas pedagógicas reflexivas, práticas pedagógicas inter e transdisciplinares na atualidade constituem-se em uma realidade concreta da minoria dos docentes.

Portanto, a docência superior na Educação Física ainda caracteriza-se por práticas que enfatizam uma construção e reprodução de saberes fragmentados e acríticos, sobretudo nos cursos de bacharelado, pela escassa produção bibliográfica de experiências e/ou pesquisas no âmbito específico da Educação Física.

No atual contexto o foco da ação docente agora não deverá estar mais no ensinar e sim no aprender, e prevalecente no aprender a aprender. Para isso o professor deverá passar a atuar como um mediador pedagógico entre o aluno e sua aprendizagem, ou seja, terá de fazer a seleção das técnicas tendo em mente o que deseja que os alunos aprendam nas dimensões intelectual, afetiva, atitudinal e de habilidade e escolher estratégias que coloque o aluno como sujeito da aprendizagem e docente como mediador. (BEHRENS, 2013; MASETTO, 2012).

Neste sentido, é válido ressaltar que o volume crescente de produções e/ou experiências com as novas tecnologias da informação e comunicação oriundas de outros campos do conhecimento tem desvelado novos ambientes de ensino e aprendizagem que se concretizam em tempos e espaços diversos dos da sala de aula, assim como de metodologias ativas que, em conjunto, abrem um vasto campo de novas possibilidades para as relações de ensino e aprendizagem no contexto da formação inicial e que será tema das próximas discussões.

O acesso fácil ao conhecimento por meio das tecnologias da informação e comunicação desafia o professor de ensino superior a repensar a sua prática docente, visto que no contexto atual o professor não deve mais exercer o papel de detentor do conhecimento de uma determinada área que repassa a seus alunos com a finalidade de se formar profissionais 


\section{CONGEESSO CIENCIAESOCIEDADE Inovação, Diversidadie e Sustentahilitidade}

competentes. Agora ele terá de buscar uma nova metodologia que atenda a sociedade atual, colaborando para que haja produção de conhecimento de maneira que seja compatível com o desenvolvimento tecnológico. (BEHRENS, 2013; MASETTO, 2012).

Assim o modelo de transmissão de conhecimento deve ser substituído pelos métodos participativos, nos quais o professor deve ser capaz de encontrar um meio que faça o aluno ultrapassar o papel de passivo, onde apenas escuta, lê, decora e repete os ensinamentos do professor, e passar a ser criativo, crítico, pesquisador e ativo para produzir conhecimento, pois hoje aprender é buscar, comparar, pesquisar, produzir, comunicar. (LEITE, 2011; BEHRENS, 2013; MORAN, 2013).

E assim "em parceria, professores e alunos precisam buscar um processo de autoorganização para acessar a informação, analisar, refletir e laborar com autonomia o conhecimento." (BEHRENS, 2013, p.77). E, por conseguinte o docente terá também de ver as tecnologias da informação e comunicação como uma nova ferramenta didático-pedagógica. (PIVA JUNIOR, 2013).

O professor deverá ter em mente que, apesar da era digital ser reconhecida como uma nova categoria do conhecimento não faz com que a linguagem corporal, oral e escrita utilizada até então seja deixada de lado, e nem também utilizar essas tecnologias como única opção, mas com critérios e como um meio que possibilita metodologias significativas para auxiliar na aprendizagem. (BEHRENS, 2013).

Para isso é preciso que o professor seja alfabetizado tecnologicamente, para que obtenha domínio técnico, crítico e pedagógico da tecnologia. E para haver esse profissional qualificado nesse quesito é necessário que a preparação se inicie ainda nas escolas de formação de professores. E após sua formação o professor ainda precisará se atualizar constantemente durante sua ação docente com relação a novas tecnologias, e também com relação a sua disciplina específica e metodologias de ensino. (LEITE, 2011; AMORA, 2011; BELLONI, 2008).

A tecnologia ainda requer atitude crítica e inovadora, onde docentes e discentes passam a fazer parte de um processo em que se aprende de maneira criativa e dinâmica tendo como essencial o diálogo e a descoberta. (BEHRENS, 2013).

A utilização das TIC's possibilitam transformar as intuições de ensino superior em "um conjunto de espaços ricos de aprendizagens significativas, presenciais e digitais, que motivem os alunos a aprender ativamente, a pesquisar o tempo todo, a serem proativos, a saber tomar 
iniciativas e integrar." (MORAN, 2013, p. 31). Uma vez utilizadas como ferramenta educacional, elas podem propiciar o desenvolvimento de aptidões de seus discentes para atuar como profissional na sociedade do conhecimento. (BEHRENS, 2013).

As TIC's vão deste as tecnologias 2.0, que são abertas, fáceis e gratuitas, como, os blogs, wikis, até as tecnologias mais organizadas como os ambientes virtuais. O professor deverá conhecer as possibilidades e potencialidades que essas tecnologias podem oferecer e saber associar com a metodologia mais adequada de modo que se possa tirar o melhor de seu uso no processo de ensino e aprendizagem. Necessitando que o docente faça um bom planejamento para que o uso dessas ferramentas tecnológicas seja efetivo. (BARBOSA, 2005; BELLONI, 2008; MORAN, 2013; PIVA JUNIOR, 2013). Assim o docente poderá:

organizar uma parte importante do currículo no ambiente digital e combina-lo com as atividades em sala de aula de forma que o projeto pedagógico de cada curso integre o presencial e o digital como componentes curriculares indissociáveis. O digital não será um acessório complementar, mas um espaço de aprendizagem tão importante como a da sala de aula. (MORAN, 2013, p.68).

Diante da potencialidade e das possibilidades que são próprias das TIC's torna-se imperioso o conhecimento acerca dos seus recursos e aplicações afim de que cada docente as utilize de forma adequada conforme a realidade na qual atue. Como a webquest que é um recurso tecnológico que possibilita o acesso a informações na internet e desenvolver projeto de pesquisa em grupo; o blog, forma reduzida de weblog, é um recurso tecnológico que permite a publicação, de forma coletiva ou individual sobre conteúdos específicos; o wiki um software que consiste em um agrupamento de páginas interconectadas, onde podem ser visualizadas e editadas por qualquer pessoa e o podcast um programa que pode ser baixado na Internet, e que possibilita a produção, comunicação e publicação integrada de áudio ou vídeo. (OLIVEIRA, COSTA, MOREIRA, 2004; MORAN, 2013; PIVA JUNIOR, 2013).

Os ambientes virtuais de aprendizagem são softwares desenvolvidos com o propósito de ofertar recursos que auxilia o professor na sua ação docente. O foco desses ambientes está na aprendizagem dos alunos. (BARBOSA, 2005). E ainda segundo Oliveira, Costa, Moreira (2004, p.119):

propiciam aos alunos uma atitude exploratória e ao professor, em seu papel mediador, a promoção das articulações necessárias para que o aluno trabalhe com autonomia, ou seja, estimulando-o a se apropriar das tecnologias intelectuais de modo a auxiliá-lo no seu trabalho e nas interações com os objetos dos conhecimentos. 
Esses ambientes virtuais de aprendizagem proporcionam que os alunos também possam aprender de maneira coletiva por meio de ferramentas como, por exemplo, os chats e fóruns, que possibilita se debater sobre um assunto, relacionado ao conteúdo da disciplina previamente selecionado pelo professor. E também permitem outras funções como disponibilizar programas de disciplinas, as tarefas que os alunos terão de fazer bem como os prazos de cada tarefa, a correção dessas tarefas e a atribuição de nota pelo docente, por exemplo. A internet um recurso dinâmico, atraente, atualizado permite ter acesso a informações das mais diferentes áreas do conhecimento, pois é um veículo no qual se dissemina e socializa a informação. (MASETTO, 2012; BARBOSA 2005).

Os softwares de simulação possibilitam que se criem realidades virtuais que imitam a realidade. Assim discentes e docentes podem experienciar situações que seriam difíceis de viver no ambiente educacional, por envolvoverem riscos na vida real, ou por serem muito complexas, ou de custo elevado, ou que levaria muito tempo para ser realizada. (PIVA JUNIOR, 2013).

\section{CONSIDERAÇÕES FINAIS/CONCLUSÕES}

Pode-se concluir que é bastante escassa a produção teórica que revela as nuances do atual contexto da docência no ensino superior na intimidade das práticas pedagógicas e suas interrelações com as novas Tecnologias da Informação e da Comunicação, sobretudo, no âmbito específico da Educação Física (Bacharelado e Licenciatura).

Por esta razão cabe aos professores de Educação Física do ensino superior o desafio de acompanhar as mudanças que as tecnologias da informação e comunicação estão causando no cenário educacional e atualizar suas práticas docentes, utilizando-se das novas tecnologias como uma ferramenta pedagógica, de modo a beneficiar no ensino e na aprendizagem, propiciando a seus alunos uma aprendizagem mais ativa onde eles possam ser capazes de transformar informação em conhecimento.

\section{REFERÊNCIAS}

AMORA, Dimmi. Professor, você está preparado para ser dono de um meio de comunicação de massa? . In: FREIRE, Wendel et al (Org.). Tecnologia e educação: as mídias na prática docente. 2. ed. Rio de Janeiro: Wak Editora, 2011. 
BACICH, Lilian. MORAN, José. Aprender e ensinar com foco na educação híbrida. Revista Pátio, no 25, p. 45-47, junho, 2015

BARBOSA, Rommel Melgaço. Ambientes virtuais de aprendizagem. Porto Alegre: Artmed, 2005.

BELLONI, Maria Luiza. Educação à distância. 5.ed. Campinas (SP): Autores Associados, 2008.

CASTELLS, M. A sociedade em rede. 4. ed. São Paulo: Paz e Terra, 2000.

CORRÊA, Flávia Leal; FRANÇA, Sérgio Luiz Braga. BEZERRA, Marlene Jesus Soares. Sociedade do conhecimento: evolução, desafios, informação, aprendizagem e propostas para um mundo mais inclusivo. In: IX Congresso Virtual Brasileiro - Administração, 2015. Disponível

em:<http://www.convibra.org/upload/paper/2015/29/2015 29 11805.pdf $>$ Acessado em 01 set. 2018.

COSTA, José Wilson da; PAIM, Isis. Informação e conhecimento no processo educativo. In: COSTA, José Wilson da; OLIVEIRA, Maria Auxiliadora Monteiro (orgs.). Novas linguagens e novas tecnologias: educação e sociabilidade. Petrópolis, RJ: Editora Vozes, 2004.

COUTINHO, Clara; LISBOA, Eliana. Sociedade da informação, do conhecimento e da aprendizagem: desafios para educação no século XXI Revista de educação, v. XVIII, n. 1, p. 5-22, 2011. Disponível em: <http://revista.educ.ie.ulisboa.pt/arquivo/vol XVIII 1/artigo1.pdf > Acessado em acessado em 25 ago. 2018.

DAVID, Nivaldo A. N. A formação do profissional docente em educação física: dicotomias e rupturas no campo da formação e da prática. In: VI Congresso Goiano de ciências do Esporte, 2009, Goiânia. Disponível

em:<congressos.cbce.org.br/index.php/congoce/VICONGOCE/paper/download/1847/395.> Acessado em 16 set. 2018.

DIESEL, Aline. BALDEZ, Alda Leila Santos. MARTINS, Silvana Neumann. Os princípios das metodologias ativas de ensino: uma abordagem. Revista Thema, Rio Grande do Sul, v.14. n.1. p. $268-288,2017$

Enade: matrículas em instituições públicas crescem e rede privada tem redução. Agência Brasil, Brasília/DF, 01 set 2017. Disponível em: <http://agenciabrasil.ebc.com.br/educacao/noticia/201709/enade-matriculas-em-instituicoes-publicas-crescem-e-rede-privada-tem-1a> Acessado em 19 set. 2018.

GEMIGNANI, Elizabeth Yu Me Yut. Formação de Professores e Metodologias Ativas de EnsinoAprendizagem: Ensinar Para a Compreensão. Revista Fronteiras da educação, Recife, v.1, n.2,2012

GIL, Antônio Carlos. Como elaborar projetos de pesquisa. 2a ed. SP: Atlas, 1991. 
LEITE, Lígia Silva. Mídia e a perspectiva da tecnologia educacional no processo pedagógico contemporâneo. In: FREIRE, Wendel et al (Org.). Tecnologia e educação: as mídias na prática docente. 2. ed. Rio de Janeiro: Wak Editora, 2011.

LEVY, Pierre. Cibercultura. 1.ed. São Paulo: Editora34, 2003.

. As Tecnologías da Inteligência. Editora. 34. São Paulo 1993.

MASETTO, Marcos Tarciso; BENHRENS, Marilda Aparecida. Novas tecnologias e mediação pedagógica. 21.ed. Campinas (SP): Papirus, 2013.

MASETTO, Marcos Tarciso. Inovação no ensino superior. São Paulo: Loyola, 2012.

MASSON , Gisele. MAINARDES, Jefferson. A ideologia da sociedade do conhecimento e suas implicações para a educação. Revista Currículo sem Fronteiras, v.11, n.2, pp.70-85, Jul/Dez. 2011

MEDINA, J. P. S. A Educação Física cuida do corpo... e "mente": bases para a renovação e transformação da educação física. 22. ed. Campinas: Papirus, 2007.

MORAN, Jose Manuel; MASETTO, Marcos Tarciso. BENHRENS, Marilda Aparecida. Novas tecnologias e mediação pedagógica. 21.ed. Campinas (SP): Papirus, 2013.

NEUSI, Aparecida. BERBEL, Navas. As metodologias ativas e a promoção da autonomia de estudantes. Revista Semina: Ciências Sociais e Humanas, Londrina, v. 32, n. 1, p. 25-40, jan./jun. 2011

OLIVEIRA, Celina Couto de; COSTA, José Wilson da; MOREIRA; Mércia. Ambientes informatizados de aprendizagem. In: COSTA, José Wilson da; OLIVEIRA, Maria Auxiliadora Monteiro. (Orgs.). Novas linguagens e novas tecnologias: Educação e sociabilidade. Petrópolis, RJ: Vozes, 2004.

PASEKINE, Silvia Costa de Oliveira. Docência universitária: o professor de educação física e sua prática pedagógica. 2010. Dissertação (Mestrado em Educação), Universidade Federal de Uberlândia, Minas Gerais.

PIVA JUNIOR, Dilermano. Sala de aula digital: uma introdução à cultura digital para educadores. 1.ed. São Paulo: Saraiva, 2013.

SCHLEMMER , Eliana. Gamificação em Espaços de Convivência Híbridos e Multimodais: Design e cognição em discussão. Revista da FAEEBA - Educação e Contemporaneidade, Salvador, v. 23, n. 42, p. 73-89, jul./dez. 2014

SILVA, Tiago Onofre da. políticas de educação superior e educação física: efeitos sobre a formação In: XVIII Congresso Brasileiro de Ciências do Esporte e V Congresso Internacional de Ciências do Esporte,2013, Brasília. Disponível em:<http://congressos.cbce.org.br/index.php/conbrace2013/5conice/paper/viewFile/5731/2807> Acessado em 01 set. 2018 